\title{
PROBLEMAS MODERNOS DE EDUCAÇÃO
}

\section{Ernesto Luiz de Oliveira Júnior}

A atual civilização tecnológica, libertando os moços do trabalho braçal que deveriam executar para manter-se, caso tivessem vivido em qualquer dos períodos anteriores a 1.800 , está dando a um número de jovens cada vez maior a oportunidade de permanecer em instituições educativas, adquirindo conhecimentos e habilidades que deverão facilitar-lhes as atividades produtivas e o desenvolvimento de suas personalidades. Por outro lado, o aumento considerável da renda nacional vem permitindo maiores inversões em instituições educacionais, abrindo, portanto, os horizontes da cultura a número crescente de jovens.

Em nosso país, entretanto, quando houve a oportunidade de planejar a educação em escala nacional, nossos políticos e educadores nem siquer tomaram conhecimento das poderosas fôrças sociais desencadeadas pelo homem em 1.800. Tais fôrças haviam permitido, em pouco mais de um século:

a) o crescimento considerável da população;

b) o prolongamento da vida provável ao nascer;

c) a elevação do nível médio de vida;

d) a transferência de parcelas enormes de mão de obra dos setôres onde o serviço é penoso para as atividades mais suaves e de salários mais altos;

e) uma redução considerável da jornada de trabalho e, como conseqüência, um aumento correspondente das horas de lazer ; 
f) a entrada em serviço em idade mais adiantada e, portanto, a possibilidade de uma escolaridade mais longa para a juventude;

g) acesso às escolas de um número imenso de jovens cuja origem modesta jamais lhes teria permitido tal aspiração em épocas anteriores.

Como conseqüência dêsse desinterêsse, foram os nossos políticos levados a legislar concedendo aos trabalhadores brasileiros regalias sòmente alcançadas em países de altíssima produtividade, objetivando elevar o nível médio de vida aos brasileiros. Mas os educadores não se preocuparam em dar a êsses trabalhadores os conhecimentos e as habilidades necessárias, indispensáveis, para que a sua produtividade se elevasse. Pelo contrário, o tipo de educação escolhido procura desenvolver, naquêles que o seguem, uma série de aspirações e de desejos que a economia pobre de nosso país subdesenvolvido não lhes pode dar.

Os educadores brasileiros convenceram-se que o homem havia atingido a perfeição em um certo lugar, em um dado instante, alguns milênios atrás, formaram uma síntese ideal das virtudes e dos conhecimentos dos mais representativos homens dessa época, tais como são representados pelos incomparáveis escritores da Grécia e de Roma. Construiram, assim, essa figura MODÊLO, o homem padrão, ao qual deveriam assemelhar-se todos aquêles que se submetessem ao processo educativo. Daí a uniformidade dos programas e dos objetivos do ensino secundário para todos os recantos e para todos os jovens de um país imenso como o Brasil.

Seria tão fácil verificar no estudo da história, entretanto, que o homem varia, ao correr dos séculos. Mesmo o que no homem existe de permanente, manifesta-se sob aspectos diferentes, em épocas ou regiões diferentes, nas diferentes civilizações que surgiram em diferentes partes do mundo e, mesmo, dentro dos quadros de uma mesma civilização.

Assim, o pretenso modêlo de homem é uma simples abstração, existem, na realidade, os homens, cada um diferente de todos os demais. 
Nossos educadores foram buscar suas idéias para a educação de nossa juventude em um país conservador, dividido em castas, e de lá trouxeram o tipo de educação que se ministrava aos filhos dos nobres e dos líderes das finanças e da política.

Poderemos, para caracterizar essa educação, chamá-la "a educação segundo o modêlo platônico".

Tratou-se, por outras palavras, de procurar a melhor educação possível, segundo as idéias de Platão, e de tomá-la como MODÊLO para a educação de tôda a juventude brasileira.

Infelizmente, não verificamos que essa educação, no país onde fômos buscá-la, era uma educação de elite, para jovens que já pertenciam a uma classe alta da sociedade, por seu nascimento; que tais moços se educavam não para ganharem suas vidas ou para desenvolverem seu país, mas, para brilharem nos salões sociais que freqüentavam, em virtude de suas relações de família. Esta educação, de tipo acadêmico, é uma educação para o pensamento e para o gôzo do que é belo; ela exige o conhecimento preliminar das grandes obras primas dos nossos antecessores, da literatura imaginativa, da arte e da ciência antigas.

A ação a que êsse tipo de educação predispõe é a da liderança. É, na verdade, uma educação aristocrática, que tem como condição essencial de sucesso o lazer.

É absolutamente justo reconhecer que essa idéia platônica de educação permitiu o brilho incontestável da civilização européia. Foi, sem dúvida, por sua causa que se desenvolveu a arte, que se encorajou o espírito de curiosidade desinteressada que levou ao fabuloso progresso das ciências e, igualmente, graças a ela, conseguiu-se manter a dignidade do espírito humano diante da fôrça material, dignidade esta que repousa sôbre a liberdade do pensamento. Não é possível deixar de reconhecer, entretanto, que essa educação não pode ser ministrada senão a poucos indivíduos, dotados de vocação especial.

A essência dêsse tipo de educação é um grande conhecimento dos melhores autores clássicos. Um estudante bem sucedido 
em seus estudos estará familiarizado com a melhor literatura jamais escrita. Terá conhecimento das línguas principais, da história do desenvolvimento de nossa civilização; conhecerá os vários sistemas filosóficos e terá lido cuidadosamente os autores que se tornaram famosos pelo brilho do pensamento e pela lucidez do estilo.

Apenas não terá aprendido a trabalhar. A atual organização do ensino no Brasil só o orientará para uma profissão se conseguir frequentar uma escola superior.

0 mal não foi termos êsse tipo de educação. Foi tê-lo tomado como "MODELLO", dentro de cujas formas rígidas e implacáveis procuramos forçar TôDA a juventude brasileira, ambição evidentemente muito acima da capacidade intelectual de nossos estudantes e dos recursos econômicos dos pais dos alunos.

É preciso reconhecer que existem muitas pessoas para quem essa é a melhor educação, pois, adapta-se rigorosamente ao seu tipo de conformação mental e, igualmente, às condições do meio em que vivem, ou no qual aspiram viver.

Mas, as atividades do espírito humano não se limitam à literatura ou ao gôso dos prazeres estéticos. Existem as pessoas de temperamento ativo, cujo alvo na vida é construir, é fazer, é sentir resultados em conseqüência de sua ação sôbre coisas materiais. Êsses espíritos não se conformam em perder longos anos de suas vidas no estudo de culturas já desaparecidas, por maiores que tenham sido.

O prazer com que a arte ou a ciência retribuem o esforço do artista, ou do cientista, é a alegria que se origina no esfôrço bem sucedido, na satisfação obtida ao alcançar alvos prefixados.

Nenhum sábio simplesmente deseja conhecer, mas, procura assimilar conhecimentos para acalmar sua paixão descoberta. Como tão bem observou Alfred Whitehead, o cientista não descobre com o objetivo de conhecer: êle procura conhecer de modo a ser capaz de descobrir. $O$ alvo final é ação e não méra contemplação do resultado. 
Nestas condições, desde muito tempo os educadores de todo mundo já deveriam ter percebido que a educação de tipo acadêmico não poderia servir como padrão ou modêlo de todos os tipos possíveis de educação.

É preciso que se diga, a bem da justiça, que tais verdades foram pelo menos vislumbradas por muitos dos responsáveis pelo planejamento da educação nacional, tanto que procuraram crear tipos paralelos de educação de gráu médio, tais como o ensino industrial, o ensino comercial, o ensino agronômico, etc.

Essa creação, entretanto, resultou em letra morta, como nossas estatísticas o revelaram em capítulos anteriores. 0 prestígio social e as vantagens de que gosou (e ainda gosa) o ensino de tipo acadêmico eram de tal monta que até mesmo as famílias mais pobres do Brasil realizavam esforços desesperados para forçar os seus filhos, através do MOLDE do ensino acadêmico, dando-lhes um certificado que poderia abrir-lhes as portas de qualquer escola universitária e, através das profissões liberais de nível superior, permitir-lhes atingir posição social, abastança e bem estar.

Ao menor contratempo, entretanto, êsses jovens abandonavam a escola acadêmica e ficavam, realmente, no mais completo desamparo, sem ao menos a capacidade necessária para ganhar a vida.

Valorizando ao extremo os estudos acadêmicos, desacreditamos, simultâneamente, os outros tipos de formação, dêstes afastando a juventude de nosso país e causando a atual crise da educação nacional.

Escapou aos educadores do sistema dos "MODELOS" a argumentação tão clara de Whitehead, segundo a qual a antítese entre uma educação tecnológica e uma educação liberal simplesmente não existe no mundo de hoje. Não pode existir uma educação tecnológica que não seja liberal, como não pode existir uma educação liberal que não seja tecnológica, isto é, 
não existe educação dígna dêsse nome que não implique, simultâneamente, a visão tecnológica e a visão acadêmica ou liberal de nossa civilização.

De fato, que é que se procura ao ministrar educação a um jovem?

Responde o Dr. Hugo Oltremare: A educação terá realizado sua tarefa quando permitir a um jovem atingir o máximo de suas possibilidades, quando permitir-lhe ser tudo aquilo que êle poderia ser...

Ora, em primeiro lugar, ninguém pode ser alguma cousa sinão no meio, na sociedade, no ambiente cultural em que vive.

Logo, o estudo dessa sociedade, das suas tradições e dos seus ideais, constitui a pedra fundamental de qualquer educação.

Em segundo lugar, todo indivíduo é consumidor. Para poder consumir, precisa produzir, isto é, trabalhar. Logo, tôda educação deve ter como objetivo o trabalho.

Esta segunda parte ficou de fóra, infelizmente, na concepção que os educadores nacionais adotaram. Basta estudar o programa modêlo fixado para as escolas secundárias brasileiras para vêr que sòmente o primeiro aspecto, o estudo das tradições e dos ideais da sociedade ocidental impressionaram nossos estudiosos.

Herdeiros, em linha reta, do pensamento grego, talvez fôssem movidos pelo exemplo daquêle filósofo que mandára aos seus discípulos que lhe arrancassem os olhos, para não ser perturbado, em seus pensamentos, pela visão de um mundo real. $\mathrm{Ou}$, talvez, pelo exemplo de Euclides, que, ao lhe perguntar um de seus discípulos qual a utilidade dos estudos que estavam realizando, ordenou a um servo: - "Dá um óbulo àquele jovem, para que tire proveito do que aqui estuda".

$\mathrm{Na}$ prática, nosso sistema educacional fracassou completamente, porque nos esquecemos de que a educação planejada não se dirigia mais a meio ou um por cento da juventude brasi- 
leira, rapazes ricos e dispondo das condições de lazer necessárias para tirar proveito de estudos teóricos e literários. Hoje, são centenas de milhares, em breve serão milhões de brasileiros que procuram e procurarão nas escolas de gráus primária e médio o melhor e o mais seguro caminho para atingirem seus objetivos na vida, objetivos forçosamente diferentes de indivíduo para indivíduo. Objetivos diferentes implicam caminhos diferentes, estudos diferentes, formação diferente.

Logo, a educação moderna não poderá deixar de ser PESSOAL, de atender a CASOS INDIVIDUAIS. A teoria MODÊLO é falsa e irreal... Não corresponde às necessidades da juventude de nossa terra.

Existem, em educação, apenas DUAS atitudes: ou o mestre procura constranger todos os espíritos que lhe são confiados a um mesmo tipo ideal e a reduzir, na medida do possível as diferenças que se apresentarem entre o aluno e o modêlo escolhido, ou o mestre escolhe o caminho de preparar para CADA ALUNO o ambiente necessário para favorecer, ao máximo, o desenvolvimento das personalidades latentes em cada sêr.

Na primeira hipótese, o mestre procura realizar uma unidade artificial, contrária à natureza, e que só seria possível dentro dos moldes rígidos de uma doutrina filosófica, política ou religiosa. Em um Estado leigo e democrático, onde são iguais perante a lei as idéias filosóficas, religiosas ou políticas que não atentem contra a Constituição em vigor, a atitude "constrangedora" do mestre inaceitável.

No outro caso a Escola transforma-se, simplesmente, em uma das agências da sociedade onde os espíritos de qualquer idade, encontram o ambiente adequado, as informações, os exemplos e os conselhos necessários para que possam atingir os limites a que as condicionou a sua própria natureza.

Depois que a dignificação do trabalho humano estabeleceu de maneira irrefutável a igual nobreza de tôdas as atividades que são essenciais para o funcionamento de nossa complexa sociedade tecnológica, não é mais possível admitir que a socie- 
dade imponha a todos uma só forma de cultura, ou que proclame que uma forma de cultura é superior, em dignidade, a tôdas as demais. Por outro lado, tendo aceito como norma social o respeito à personalidade humana, como seria possível conceber uma educação na qual o mestre usasse a fôrça e o prestígio que a sociedade lhe concede para "forçar" as pequeninas almas que lhe são confiadas?

Em uma éra na qual se procura fazer freqüentar a escola pela maior parte possível da população, seria simplesmente um contrasenso insistir em idéias que há mais de um século estão completamente obsoletas. Os educadores do presente jamais deveriam esquecer a advertência de Alfred Sauvy (Esprit, junho 1954, pág. 869) o qual, referindo-se ao ensino secundário francês que tão de perto serviu de modêlo ao nosso, dizia:

“O ensino do segundo gráu tem como conseqüência essencial criar ou desenvolver uma inaptitude física, mas principalmente moral, para qualquer trabalho manual".

Verificamos, assim, que os educadores modernos, na maioria dos países, deixaram completamente de lado as fôrças imensas liberadas pela Revolução Tecnológica, para continuarem fieis às tradições aristocráticas herdadas através de milênios.

Hoje em dia, porém, o problema dos educadores não é, simplesmente, receber $1 / 2$ ou 1 por cento dos jovens de cada classe anual e nêles desenvolver sentimentos de apreciação do belo, ou de amor aos clássicos gregos. Trata-se de receber milhões de jovens cada ano e de dar-lhes os meios para que se distribuam entre as numerosas ocupações que a nossa sociedade, cada vez mais complexa, está pedindo cada vez maior número e nenhuma das quais pode ser exercida sem uma aprendizagem às vêzes longa. Trata-se de escolher um tipo de educação que permita aos moços adaptar-se a novas condições de trabalho quando o progresso tecnológico os forçar a mudar de profissão, fato que aos poucos se vai verificando com freqüência cada vez maior. 
Trata-se, finalmente, de dar aos trabalhadores um ideal e uma motivação com que preencher as horas de lazer que o próprio progresso tecnológico vai se encarregando de aumentar cada vez mais.

É a esta educação eminentemente flexível, que dia a dia se adapta às necessidades dos alunos que dia a dia orienta seus objetivos de acôrdo com as variações do progresso tecnológico, que tanto ensina a um aluno como manter um automóvel, se seu desejo é ser chaufeur, como ensina a representar Shakeespeare, se sua vocação é para o teatro, é a esta educação que gostaríamos de chamar de educação DINÂMICA para acentuar a sua oposição à educação ESTÁTICA de MODÊLOS FIXOS que viemos seguindo até agora. 